\title{
Avifauna do campus da Universidade de Santa Cruz do Sul, RS, Brasil
}

\author{
Avifauna of the Universidade de Santa Cruz do Sul campus, Southern Brazil
}

\author{
Adriana Düpont \\ Alexsandro Rodrigo Mohr \\ Eduardo Alexis Lobo Alcayaga \\ Universidade de Santa Cruz do Sul - Unisc - Santa Cruz do Sul - Rio Grande do Sul - Brasil
}

\section{Resumo}

Informação científica atualizada sobre comunidades de aves é essencial para permitir uma avaliação ambiental das condições necessárias para manter a biodiversidade local, como forma de evitar extinções futuras e garantir a integridade dos ecossistemas. Áreas com ambientes de mata e áreas abertas podem contribuir para a manutenção das aves em ambientes urbanos, destacando o papel de parques, áreas verdes e campi universitários que podem atuar como "ilhas" e corredores de grande importância como locais de abrigo e alimentação. Neste contexto, o presente estudo teve por objetivo realizar um levantamento qualitativo das espécies de aves que ocorrem no Campus Universitário da UNISC, zona urbana do município de Santa Cruz do Sul, RS, Brasil. O inventário de campo foi realizado entre janeiro a dezembro de 2013. Seis transectos foram percorridos. As amostragens foram realizadas no período matutino e vespertino, e as espécies foram identificadas pela morfologia externa e reconhecimento de suas vocalizações. Os resultados indicaram a ocorrência de 101 espécies de aves pertencentes a 38 famílias, o que representa 15,3\% das espécies registradas para o Rio Grande do Sul. Em relação à estrutura trófica, oito guildas ecológicas foram identificadas, destacando as espécies com hábitos alimentares insetívoros e onívoros como as mais representativas, $46,5 \%$ e $21,8 \%$, respectivamente. 13 espécies migratórias Neotropicais foram registradas. Não foram observadas espécies ameaçadas de extinção. Os resultados indicaram que apesar da ocorrência de espécies predominantemente generalistas, o campus universitário serve como área de abrigo, além de descanso e alimentação.

\section{Abstract}

Updated scientific information on bird communities is essential to allow us an environmental evaluation of the necessary conditions to maintain local biodiversity, as a way to prevent future extinctions and to guarantee the ecosystems integrity. Areas with forest environments and open areas can contribute to the urban environment bird's maintenance, highlighting the role of parks, green areas and university campus that can act as "islands" and ecological corridors of great importance as shelter and food supply. In this context, the present study aimed to realize a qualitative survey on bird species that occurs at the University campus of UNISC, located in the urban zone of Santa Cruz do Sul County, RS, Brazil. The survey was conducted from January and December 2013. Six transects were covered. The samplings were made in the matutine and vespertine crepuscular periods, and the species were identified by external morphology and reconnaissance of their vocalizations. The results indicated the occurrence of 101 species of birds, distributed in 38 families, being 15,3\% of the species recorded for the RS. As for trophic structure, eight ecological guilds were identified, highlighting that species with insectivorous eating habits and omnivores were the most representative, $46,5 \%$ e $21,8 \%$, respectively. 13 Neotropical migratory species were registered. No species threatened of extinction were observed. The results indicate that in spite of the occurrence of species predominantly generalist, the university campus serves as shelter area, as well as for resting and food supply.

\section{Palavras-chave}

Avifauna. Remanescentes florestais. Campus

universitário. Ecossistema urbano. Santa Cruz do Sul, RS.

\section{Keywords}

Avifauna. University campus. Forest fragments. Urban ecosystem. Santa Cruz do Sul, RS. 


\section{Introdução}

O Brasil apresenta uma rica diversidade de aves, com um total de 1.901 espécies registradas. Dentre estas, somente nos últimos três anos foram acrescidas 70 novas espécies devido a pesquisas de profissionais ligados a academias brasileiras, gravações sonoras e a acessibilidade ascendente de análises moleculares (CBRO, 2014).

No Rio Grande do Sul são registradas 661 espécies (BENCKE et al., 2010). Conforme Bencke et al., (2006), os estudos sobre as comunidades de aves possibilitam uma avaliação do ambiente, assim como as suas condições e a capacidade em manter a biodiversidade local, pois a prevenção de extinções futuras e a manutenção da integridade dos ecossistemas depende das informações científicas atualizadas sobre as espécies.

A fragmentação dos ambientes naturais tem forçado muitas espécies de aves silvestres a buscarem refúgio, abrigo, alimentação e local de reprodução em praças, parques e jardins; ecossistema com características próprias, o urbano. Existem poucos estudos sobre a avifauna urbana, pois apenas $31,0 \%$ das espécies brasileiras podem ser encontradas nesse ambiente. Entretanto, constituem o grupo animal mais estudado neste ecossistema (PINHEIRO et al., 2009 e TURNER, 2003).

Essa diversidade tem flutuado consideravelmente entre os Campi, principalmente em função da cobertura vegetal e do impacto antrópico, tendo havido o registro de 216 espécies de aves na Universidade Federal de São Carlos, SP (Motta-Junior e Vasconcellos, 1996), 107 na Universidade Federal de Lavras, MG (D'Angelo Neto et al., 1998), 91 na Universidade Federal de Uberlândia, MG (Franchin et al., 2004), 174 na Universidade Estadual de Londrina, PR (Lopes e Anjos 2006) e 120 espécies no Campus Carreiros da Fundação Universidade de Rio Grande, RS (Votto et al., 2006). Geralmente os campi universitários abrigam uma grande diversidade de aves em um ambiente fragmentado, caracterizado por um mosaico de ilhas de diferentes tamanhos e com vegetação alterada por espécies oportunistas ou exóticas (FRANCO e PRADO, 2012).

Neste contexto, o presente estudo teve como objetivo o levantamento qualitativo da avifauna presente no campus Sede da Universidade de Santa Cruz do Sul - UNISC, visando contribuir ao conhecimento da biodiversidade local.

\section{Material e métodos}

O estudo foi realizado no campus Sede da Universidade de Santa Cruz do Sul - UNISC, zona urbana do município de Santa Cruz do Sul, RS, Brasil (Fig. 1). A área total do campus compreende $423.085,9 \mathrm{~m}^{2}$, com uma área construída de 59.903,9 $\mathrm{m}^{2}$. O inventário de campo foi realizado entre janeiro a dezembro de 2013, onde foram percorridos seis transectos (três com fragmentos florestais e três em área aberta), visando abranger diferentes habitats (Fig. 2), como remanescentes florestais em regeneração primária (capoeira), área com construções (prédios) e campo. A nomenclatura científica e a ordem taxonômica utilizada segue a lista do Comitê Brasileiro de Registros Ornitológicos (CBRO, 2014). Quanto ao status de ocorrência no RS as aves foram classificadas segundo Bencke (2001) e quanto à alimentação foram classificadas em guildas alimentares, conforme Sick (1997) e Sigrist (2013). Já para classificar espécies endêmicas foi usado o trabalho de Benc ke et al. (2006), e para status de conservação a lista das espécies ameaçadas de extinção do Rio Grande do Sul (RIO GRANDE DO SUL, 2014) e IUCN (2014).

As amostragens foram realizadas no período matutino e vespertino e as aves foram identificadas através da vocalização e/ou observação direta. Sempre que possível, documentou-se a ocorrência das espécies através de fotografias e gravações das vocalizações, utilizando o gravador Panasonic US511 e microfone direcional Yoga HT-81. 


\section{Resultados e discussão}

Foram registradas 101 espécies de aves no campus, distribuídas em 38 famílias (Tabela 1), o que representa $15,3 \%$ das espécies de aves registradas para o Rio Grande do Sul (BENCKE et al., 2010). A paisagem do campus apresenta-se muito alterada pelas construções e ocupação humana, tendo sido verificado que dos distintos ambientes que foram amostrados, os fragmentos de mata atlântica destacaram-se por contribuir com a maior proporção da riqueza de espécies de aves observadas $(78,2 \%)$.

Os resultados evidenciaram uma riqueza expressiva para uma área urbana, comparativamente a outros estudos realizados em campi universitários do Brasil, destacando o registro de 84 espécies de aves no Campus da Universidade do Vale do Rio dos Sinos em São Leopoldo, RS, 152 espécies no Campus da Universidade de São Paulo, SP, 107 espécies no Campus da Universidade Federal de Lavras, MG, e 68 espécies no Campus da Universidade Federal do Acre, AC (VOTTO et al., 2006).

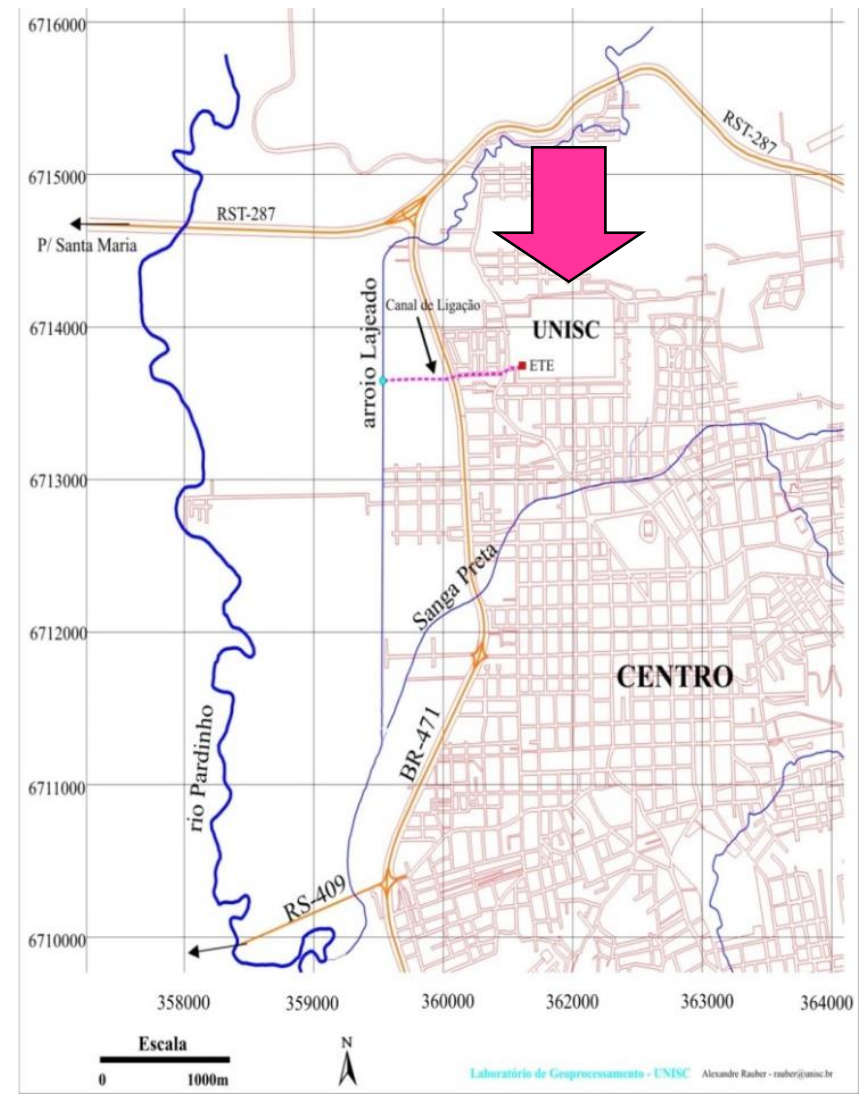

Figura 1 - Mapa do centro urbano da cidade de Santa Cruz do Sul, RS, destacando o Campus Sede da Universidade de Santa Cruz do Sul - UNISC. 


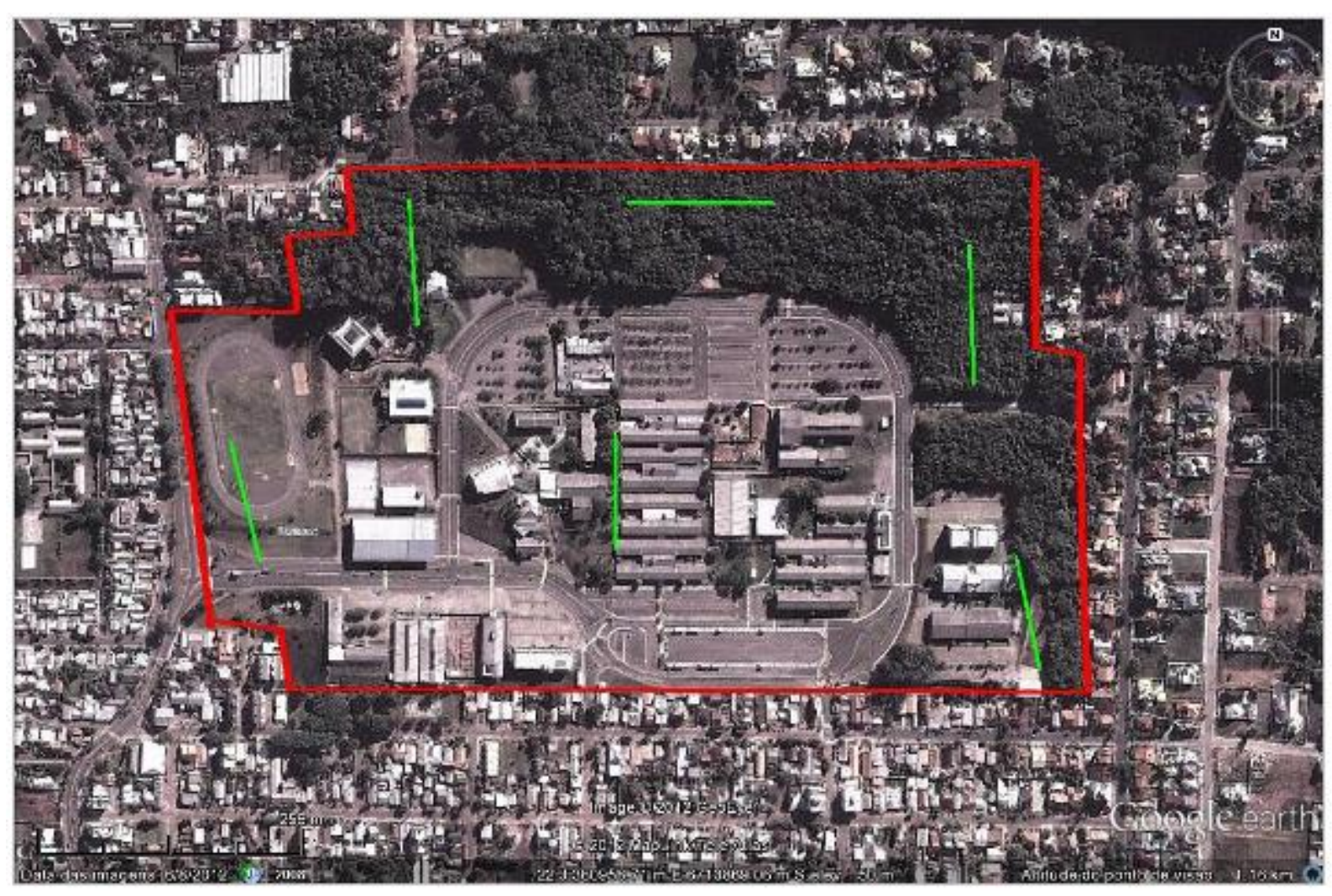

Figura 2 - Mapa do campus Sede da UNISC, destacando na cor verde os seis transectos percorridos. Fonte: Google Earth (2012)

As famílias Tyrannidae e Thraupidae foram as mais representativas, atingindo $24,8 \%$ do total de aves registradas. Furnariidae representou 5,9\% do total, seguida de Columbidae e Icteridae, ambas com 4,9\%. Em estudo realizado no campus da Universidade do Vale do Itajaí, SC, as famílias Tyrannidae e Thraupidae foram, também, as mais representativas (PINHEIRO et al., 2009). Estas famílias englobam uma grande variedade de espécies cuja distribuição é exclusiva do continente americano e ocupam os mais variados ambientes, excetuando-se regiões de latitudes extremas em que o clima não favorece sua ocorrência. Thraupidae são espécies de aves onívoras e seu forrageamento ocorre em grupos (casais, grupos gregários e até mesmo bandos mistos), além de solitariamente. Suas principais fontes de alimento são frutos, néctar e insetos (VASSÃO, 2013 e MARINI et. al., 2009).

Foram registradas 13 espécies migratórias Neotropicais sendo que as primeiras foram observadas chegando ao final do inverno (Tabela 2 e Figura 3).

As garças Egretta thula e Bulbucus ibis estavam frequentemente pousadas em árvores de eucalipto, enquanto que os maçaricos Plegadis chihi e Phimosus infuscatus foram observados sobrevoando a área do campus ao entardecer. No campus da UNISC não existem locais alagados, contudo estas espécies estão associadas a áreas úmidas, a exceção de Bulbucus ibis, condição que sugere a utilização dos fragmentos florestais do campus para descanso e abrigo. Foram observados variados tipos de comportamentos nas demais espécies presentes no campus como a comunicação visual e acústica, comportamento alimentar, reprodução, nidificação, cuidado com a prole, territorialismo e comportamento de defesa. Neste sentido, o campus Sede da UNISC é uma importante área de manutenção da avifauna local, pois estes comportamentos observados são respostas integradas que as aves oferecem aos diferentes estímulos do ambiente. 
Tabela 1 - Lista de espécies de aves registradas e guildas alimentares observadas no campus.

\begin{tabular}{|c|c|c|c|}
\hline FAMÍLIAS & ESPÉCIES & NOME VULGAR & GUILDAS \\
\hline CRACIDAE & Ortalis squamata & Aracuã-escamoso & Frugívora \\
\hline \multirow[t]{2}{*}{ ARDEIDAE } & Bulbucus ibis & Garça-vaqueira & Insetívora \\
\hline & Egretta thula & Garça-branca-pequena & Piscívora \\
\hline CATHARTIDAE & Coragyps atratus & Urubu-de-cabeça-preta & Necrófago \\
\hline \multirow[t]{2}{*}{ ACCIPITRIDAE } & Elanoides forficatus & Gavião-tesoura & Carnívora \\
\hline & Ictinia plumbea & Sovi & Carnívora \\
\hline RALLIDAE & Aramides saracura & Saracura-do-mato & Onívora \\
\hline CHARADRIIDAE & Vannellus chilensis & Quero-quero & Onívora \\
\hline \multirow[t]{5}{*}{ COLUMBIDAE } & Zenaida auriculata & Pomba-de-bando & Granívora \\
\hline & Patagioenas picazuro & Pombão & Granívora \\
\hline & Columbina picui & Rolinha-picuí & Granívora \\
\hline & Columbina talpacoti & Rolinha-roxa & Granívora \\
\hline & Leptotila verreauxi & Juriti-pupu & Granívora \\
\hline TINAMIDAE & Crypturellus obsoletus & Inhambuguaçu & Granívora \\
\hline \multirow[t]{3}{*}{ CUCULIDAE } & Piaya cayana & Alma-de-gato & Insetívora \\
\hline & Guira guira & Anu-branco & Insetívora \\
\hline & Crotophaga ani & Anu-preto & Insetívora \\
\hline \multirow[t]{2}{*}{ STRIGIDAE } & Athene cunicularia & Coruja-buraqueira & Carnívora \\
\hline & Megascops choliba & Corujinha-do-mato & Carnívora \\
\hline CAPRIMULGIDAE & Hydropsalis torquata & Bacurau-tesoura & Insetívora \\
\hline \multirow[t]{3}{*}{ PSITTACIDAE } & Pyrrhura frontalis & Tiriba-de-testa-vermelha & Frugívora \\
\hline & Myiopsitta monachus & Caturrita & Frugívora \\
\hline & Pionus maximiliani & Maitaca-verde & Frugívora \\
\hline APODIDAE & Chaetura meridionalis & Andorinhão-do-temporal & Insetívora \\
\hline TROGONIDAE & Trogon surrucura & Surucuá-variado & Insetívora \\
\hline \multirow[t]{2}{*}{ TROCHILIDAE } & Chlorostilbon lucidus & $\begin{array}{l}\text { Besourinho-de-bico } \\
\text { vermelho }\end{array}$ & Nectarívora \\
\hline & Hylocharis chrysura & Beija-flor-dourado & Nectarívora \\
\hline RAMPHASTIDAE & Ramphastos dicolorus & Tucano-de-bico-verde & Granívora \\
\hline \multirow[t]{4}{*}{ PICIDAE } & Colaptes campestris & Pica-pau-do-campo & Insetívora \\
\hline & Melanerpes candidus & Pica-pau-branco & Insetívora \\
\hline & Colaptes melanochloros & Pica-pau-verde-barrado & Insetívora \\
\hline & Veniliornis spilogaster & Picapauzinho-verde-carijó & Insetívora \\
\hline \multirow[t]{2}{*}{ FALCONIDAE } & Milvago chimachima & Carrapateiro & Carnívora \\
\hline & Milvago chimango & Chimango & Carnívora \\
\hline \multirow[t]{6}{*}{ FURNARIIDAE } & Furnarius rufus & João-de-barro & Onívora \\
\hline & Synallaxis cinerascens & Pi-puí & Insetívora \\
\hline & Lochmias nematura & João-porca & Insetívora \\
\hline & Synallaxis spixi & João-teneném & Insetívora \\
\hline & Synallaxis ruficapilla & Pichororé & Insetívora \\
\hline & Syndactyla rufosuperciliata & Trepador-quiete & Insetívora \\
\hline PLATYRINCHIDAE & Platyrinchus mystaceus & Patinho & Insetívora \\
\hline
\end{tabular}




\begin{tabular}{|c|c|c|c|}
\hline TYRANNIDAE & Serpophaga subcristata & Alegrinho & Insetívora \\
\hline \multirow[t]{15}{*}{ TYRANNIDAE } & Camptostoma obsoletum & Risadinha & Insetívora \\
\hline & Elaenia sp. & - & Insetívora \\
\hline & Elaenia parvirostris & Guaracava-de-bico-curto & Frugívora \\
\hline & Elaenia flavogaster & $\begin{array}{l}\text { Guaracava-de-barriga } \\
\text { amar. }\end{array}$ & Frugívora \\
\hline & Hirundinea ferruginea & Gibão-de-couro & Insetívora \\
\hline & Myiarchus swainsoni & Irré & Insetívora \\
\hline & Tyrannus melancholicus & Suiriri & Insetívora \\
\hline & Machetornis rixosa & Suiriri-cavaleiro & Insetívora \\
\hline & Satrapa icterophrys & Suiriri-pequeno & Insetívora \\
\hline & Megarynchus pitangua & Neinei & Onívora \\
\hline & Pitangus sulphuratus & Bem-te-vi & Onívora \\
\hline & Myiodynastes maculatus & Bem-te-vi-rajado & Onívora \\
\hline & Legatus leucophaius & Bem-te-vi-pirata & Insetívora \\
\hline & Empidonomus varius & Peitica & Insetívora \\
\hline & Tyrannus savana & Tesourinha & Insetívora \\
\hline \multirow[t]{4}{*}{ THAMNOPHILIDAE } & Dysithamnus mentalis & Choquinha-lisa & Insetívora \\
\hline & Thamnophilus caerulescens & Choca-da-mata & Insetívora \\
\hline & Tolmomyias sulphurescens & Bico-chato-de-orelha-preta & Insetívora \\
\hline & Phylloscartes ventralis & Borboletinha-do-mato & Insetívora \\
\hline RHYNCHOCYCLIDAE & Poecilotriccus plumbeiceps & Tororó & Insetívora \\
\hline \multirow[t]{2}{*}{ VIREONIDAE } & Cyclarhis gujanensis & Pitiguari & Insetívora \\
\hline & Vireo chivi & Juruviara & Insetívora \\
\hline \multirow[t]{3}{*}{ HIRUNDINIDAE } & Progne chalybea & Andorinha-doméstica-gde & Insetívora \\
\hline & Pygochelidon cyanoleuca & $\begin{array}{l}\text { Andorinha-pequena-de- } \\
\text { casa }\end{array}$ & Insetívora \\
\hline & Progne tapera & Andorinha-do-campo & Insetívora \\
\hline TROGLODYTIDAE & Troglodytes musculus & Corruíra & Insetívora \\
\hline \multirow[t]{4}{*}{ TURDIDAE } & Turdus rufiventris & Sabiá-laranjeira & Onívora \\
\hline & Turdus amaurochalinus & Sabia-poca & Onívora \\
\hline & Turdus leucomelas & Sabiá-barranco & Onívora \\
\hline & Turdus subalaris & Sabiá-ferreiro & Onívora \\
\hline MIMIDAE & Mimus saturninus & Sabiá-do-campo & Onívora \\
\hline COEREBIDAE & Coereba flaveola & Cambacica & Nectarívora \\
\hline \multirow[t]{9}{*}{ THRAUPIDAE } & Lanio cucullatus & Tico-tico-rei & Insetívora \\
\hline & Tangara sayaca & Sanhaçu-cinzento & Onívora \\
\hline & Pipraeidea bonariensis & Sanhaçu-papa-laranja & Onívora \\
\hline & Saltator similis & Trinca-ferro-verdadeiro & Onívora \\
\hline & Tersina viridis & Saí-andorinha & Onívora \\
\hline & Hemithraupis guira & Saíra-do-papo-preto & Onívora*** \\
\hline & Tangara preciosa & Saíra preciosa & Onívora \\
\hline & Pipraeidea melanonota & Saíra-viúva & Onívora \\
\hline & Tachyphonus coronatus & Tiê-preto & Frugívora \\
\hline EMBERIZIDAE & Sicalis flaveola & Canário-da-terra- & Granívora \\
\hline
\end{tabular}

Cadernos de Pesquisa [ISSN 1677-5600]. Santa Cruz do Sul, v. 29, n. 1, p. 09-18, jan./abr. 2017 https://online.unisc.br/seer/index.php/cadpesquisa/index 


\begin{tabular}{llll} 
& & verdadeiro & \\
& Sporophila caerulescens & Coleirinho & Granívora \\
& Poospipiza nigrorufa & Quem-te-vestiu & Insetívora \\
& Sporophila caerulescens & Coleirinho & Granívora \\
PASSERELLIDAE & Zonotrichia capensis & Tico-tico & Insetívora \\
CARDINALIDAE & Cyanoloxia glaucocaerulea & Azulinho & Granívora \\
PARULIDAE & Setophaga pitiayumi & Mariquita & Insetívora \\
& Myiothlypis leucoblephara & Pula pula assobiador & Insetívora \\
ICTERIDAE & Basileuterus culicivorus & Pula pula & Insetívora \\
& Icterus pyrrhopterus & Encontro & Onívora \\
& Cacicus haemorrhous & Guaxe & Onívora \\
& Molothrus bonariensis & Vira-bosta & Insetívora \\
& Molothrus rufoaxillaris & Vira-bosta-picumã & Insetívora \\
FRINGILLIDAE & Chrysomus ruficapillus & Garibaldi & Onívora \\
& Euphonia chlorotica & Fim-fim & Frugívora \\
& Euphonia pectoralis & Ferro-velho & Frugívora \\
\hline & Estrilda astrild & Pardal & Granívora \\
& Passer domesticus & & Onívora \\
\hline
\end{tabular}

Tabela 2. Lista de espécies de aves migratórias neotropicais registradas no campus Sede da UNISC, no período de janeiro a dezembro de 2013.

\begin{tabular}{lll}
\hline FAMÍLIAS & ESPÉCIES & NOME-VULGAR \\
\hline ACCIPITRIDAE & Elanoides forficatus & Gavião-tesoura \\
APODIDAE & Chaetura meridionalis & Andorinhão-do-temporal \\
TYRANNIDAE & Myiarchus swainsoni & Irré \\
TYRANNIDAE & Myiodynastes & Bem-te-vi-rajado \\
& maculatus & \\
TYRANNIDAE & Megarynchus pitangua & Neinei \\
TYRANNIDAE & Tyrannus melancholicus & Suiriri \\
TYRANNIDAE & Tyrannus savana & Tesourinha \\
TYRANNIDAE & Empidonomus varius & Peitica \\
VIREONIDAE & Vireo chivi & Juruviara \\
HIRUNDINIDAE & Progne tapera & Andorinha-do-campo \\
HIRUNDINIDAE & Progne chalybea & Andorinha-doméstica-grande \\
TURDIDAE & Turdus subalaris & Sabiá-ferreiro \\
THRAUPIDAE & Tersina viridis & Saí-andorinha \\
\hline
\end{tabular}

Quanto à estrutura alimentar, as espécies foram classificadas em oito categorias tróficas distintas (Fig. 4). Aves que tem preferência alimentar insetívora foram as mais frequentes, com $46,5 \%$. A segunda maior categoria foi das espécies onívoras $21,8 \%$, seguidas de granívoras $(11,9 \%)$ e frugívoras $(8,9 \%)$.

Segundo Scherer et al., (2005), espécies que possuem disponibilidade de alimento durante $o$ ano inteiro, como as aves insetívoras, ou as que utilizam táticas alimentares mais 
variadas, como as onívoras, tendem a um predomínio, o que foi verificado neste estudo. Motta Júnior (1990) também encontrou uma predominância de insetívoros sobre os onívoros num pequeno fragmento de mata ciliar na região central do Estado de São Paulo. Os insetívoros que se alimentam de pequenos insetos aparentemente aumentam em abundância em locais fragmentados. Os insetívoros generalistas geralmente habitam borda de mata, áreas abertas e estrato superior arbóreo, possuindo grande adaptabilidade a ambientes degradados (WILLIS 1979, RIBON et al., 2003). Estas características podem explicar o maior número de insetívoros em relação às aves que se alimentam de outros itens na área estudada.

Em relação aos onívoros é esperada a alta percentagem em fragmentos pequenos, pois a onívoria tem efeito tampão contra flutuações na disponibilidade de alimento nestes ambientes (Willis, 1979), enquanto que a alta porcentagem de espécies de aves insetívoras é padrão para a região tropical (Sick, 1997).

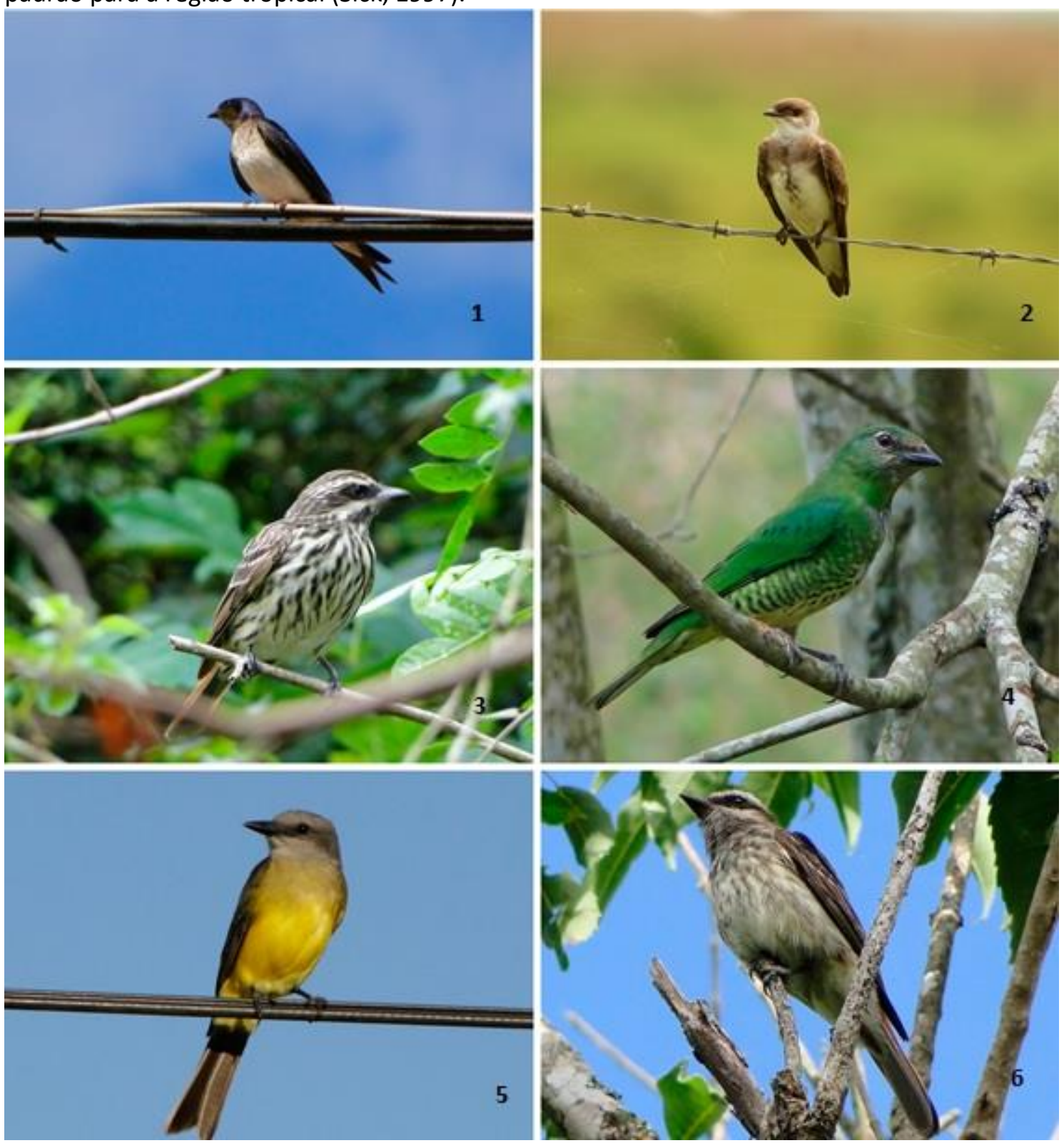

Figura 3. Espécies migratórias observadas no Campus Sede da UNISC. 1- Andorinha-doméstica-grande (Progne chalybea); 2- Andorinha-do-campo (Progne tapera); 3- Bem-te-vi-rajado (Myiodynastes maculatus); 4- Saíandorinha (Tersina viridis) fêmea; 5- Suiriri (Tyrannus melancholicus); 6- Peitica (Empidonomus varius). 


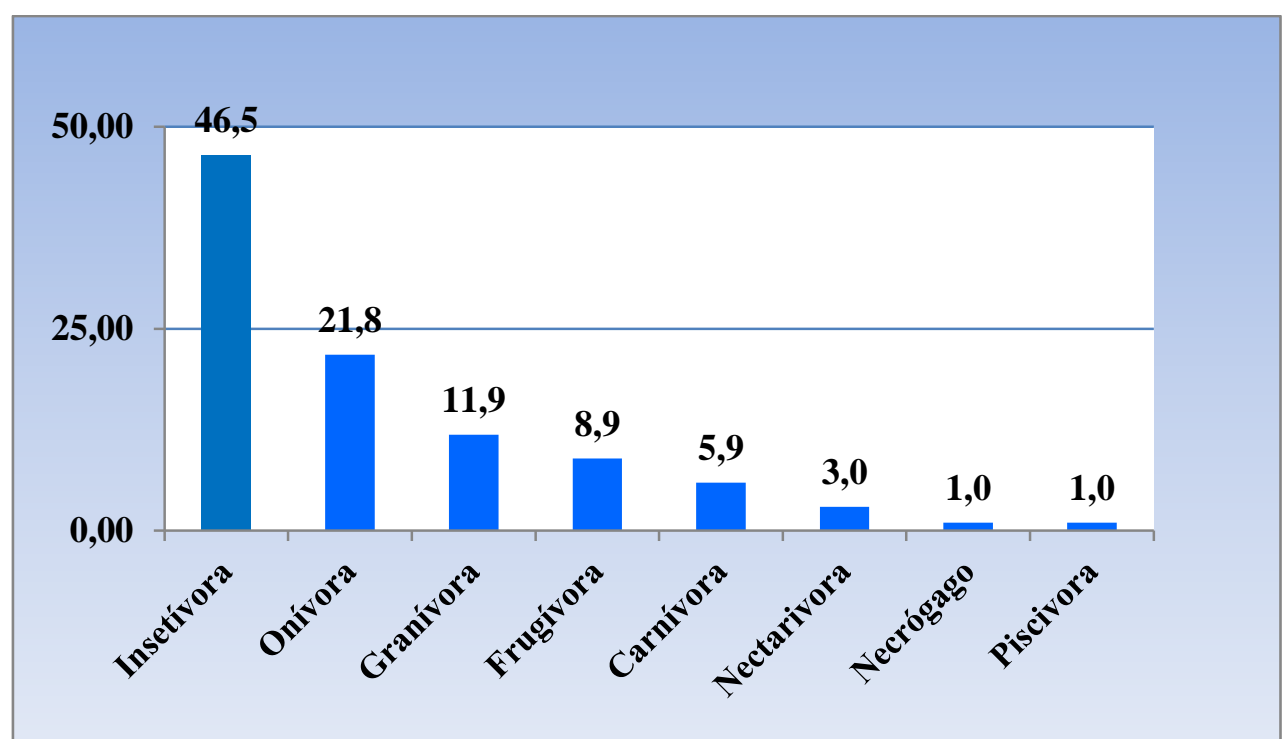

Figura 4. Guildas alimentares representativas do Campus Sede da UNISC, no período de janeiro a dezembro de 2013.

Cabe destacar que Furnarius rufus (joão de barro) foi a única espécie presente em todas as áreas pesquisadas. Conforme Belton (2004) é uma ave comum, que habita todos os tipos de ambientes do Rio Grande do Sul, exceto mata fechada uma vez que pousa constantemente em postes, cercas, galhos isolados e outros pontos que permitam uma boa visão dos arredores.

Conforme a Lista de Aves do Brasil do Comitê Brasileiro de Registros Ornitológicos, publicada em 01 de Janeiro de 2014, não foi verificada a ocorrência de espécies ameaçadas de extinção dentre as espécies observadas no campus.

\section{Conclusão}

O campus Sede da UNISC demonstra ser uma importante área de manutenção da avifauna local, tendo havido o registro de 101 espécies de aves, pertencentes a 38 famílias. Foram observadas várias atividades comportamentais, como sobrevoo, forrageamento, deslocamento e eventos reprodutivos o que é essencial para a garantia das espécies manterem seu ciclo biológico no local, pois precisam destas áreas para alimentação, refúgio e nidificação.

\section{Referências}

1. BELTON W. Aves silvestres do Rio Grande do Sul. (2004). 4ạ edição. Porto Alegre. Fundação Zoobotânica do Rio Grande do Sul. 175p.

2. BENCKE G.A. (2001). Lista de referência das aves do Rio Grande do Sul. Porto Alegre, Ed. Fundação Zoobotânica do Rio Grande do Sul.

3. BENCKE, G. A.; DIAS, R. A.; BUGONI, L.; AGNE, C. E. ; FONTANA, C. S.; MAURICÍO, G. N.; MACHADO, D. B. (2010). Revisão e atualização da lista das aves do Rio Grande do Sul, Brasil. Iheringia, v. 100, n.4, p. 519-556. 
4. BENCKE, G. A.; MAURÍCIO, G. N.; DEVELEY, P. F.; GOERCK, J. M. (2006). Áreas importantes para a conservação de aves no Brasil. Parte I - Estados do domínio da Mata Atlântica. SAVE Brasil, São Paulo, Brasil, 494p.

5. CBRO - Comitê Brasileiro de Registros Ornitológicos. (2014). Lista das aves do Brasil. 11으 ed. 2014. Disponível em: <http://www.cbro.org.br > Acesso em Fevereiro de 2014.

6. FRANCO, A. N \& DO PRADO, A. D. (2012). Atualidades Ornitológicas. On-line № 166 Março/Abril 2012.

7. D' ANGELO-NETO, S., N. VENTURIN, A.T. de OLIVEIRA-FILHO \& F.A.F. COSTA. (1998). Avifauna de quatro fisionomias florestais de pequeno tamanho (5-8 ha) no Campus da UFLA. Revista Brasileira Biologia, Rio de Janeiro, 58(3):463-472.

8. FRANCO, A.N.; PRADO, A.D. 2012. Levantamento preliminar da avifauna do Campus de Porto Nacional da Universidade Federal do Tocantins. Atualidades Ornitológicas On-line № 166 - Março/Abril 2012.

9. FRANCHIN, A.G, G.M. OLIVEIRA, C.MELO, E.R. TOMÉ \& O. MARÇAL-JÚNIOR. (2004). Avifauna do Campus Umuarama, Universidade Federal de Uberlândia (Uberlândia, MG). Revista Brasileira Zoociências, Juiz de Fora, 6(2):219-230.

10. IUCN. Red list of threatened species. 2014. Version 2014.2. Disponível em <www.iucnredlist.org>. Acesso em: 22 de maio 2015.

11. LOPES, E.V. \& L. ANJOS. (2006). A composição da avifauna do Campus da Universidade Estadual de Londrina, norte do Paraná, Brasil. Revista Brasileira Zoologia, Curitiba, 23(2):145-156.

12. MARINI, M.Â., LOBO, Y., LOPES, L.E., FRANÇA, L.F., PAIVA, L.V. (2009). Biologia reprodutiva de Tyrannus savana (Aves, Tyrannidae) em cerrado do Brasil Central. Biota Neotrop.9(1):http://www.biotaneotropica.org.br/v9n1/pt/abstract?article+bn010090120 09.

13. MOTTA JÚNIOR, J. C. (1990). Estrutura trófica e composição das avifaunas de três habitats terrestres na região central do Estado de São Paulo. Ararajuba, 1: 65-71.

14. MOTTA-JUNIOR, J.C. \& L.A.S.V. (1996). Levantamento das aves do campus da Universidade Federal de São Carlos, Estado de São Paulo, Brasil. Anais do VII Seminário Regional de Ecologia. Universidade Federal de São Carlos, São Carlos, p.159-171.

15. PINHEIRO et al. (2009) Abundância e diversidade da avifauna no campus da Universidade do Vale do Itajaí, Santa Catarina. Ornithologia 3 (2):90-100, dezembro 2009.

16. RIBON, R.; SIMON, E. J.; MATTOS, G. T. Bird Extinctions in Atlantic forest fragments of the Vi_cosa region, Southeastern Brazil. Cons. Biol. ,17(6): 1827 - 1839, 2003.

17. RIO GRANDE DO SUL. ASSEMBLEIA LEGISLATIVA. Decreto no 51.797, de 8 de setembro de 2014. Declara as Espécies da Fauna Silvestre Ameaçadas de Extinção no Estado do Rio Grande do Sul. DOE n.o 173, de 09 de setembro de 2014. 
18. SCHERER, A. et al. (2005). Estrutura trófica da avifauna em oito parques da cidade de Porto Alegre, Rio Grande do Sul, Brasil. Ornithologia, Porto Alegre, v. 1, n. 1. p. 25-32.

19. SICK, H. (1997). Ornitologia Brasileira. Rio de Janeiro: Ed. Nova Fronteira, 912 p.

20. SIGRIST, T. (2013). Guia de Campo Avis Brasilis - Avifauna Brasileira. 592p.

21. TURNER, W.R. (2003). Citywide biological monitoring as a tool for ecology and conservation in urban landscapes: the case of the Tucson Bird Count. Landscape and Urban Planning, Texas, 65:149-166.

22. WILLIS, E. O. The composition of avian communities in remanescent woodllots in southren Brazil. Pap. Avul. Zoo., 33:1 - 25, 1979.

23. VASSÃO, G.A.S. Comportamento de forrageamento da figuinha-de-crisso-castanho (Conirostrum speciosum) (AVES THRAUPIDAE) e sua associação com bandos mistos. - Rio Claro : [s.n.], 2013. 24pág.

24. VOTTO, A.N.; JÚNIOR A.G.; BUGONI L.; JÚNIOR J.P. (2006). Sazonalidade da avifauna no Campus Carreiros da Fundação Universidade Federal do Rio Grande do Sul, Rio Grande do Sul, Brasil. Estud. Biol., v. 28, n.62, p. 45-55, jan./mar. 